\title{
COMPARATIVE PERFORMANCE EVALUATION OF AN EXISTING AND MODIFIED ACHA DEHULLERS
}

THERESA K. KAANKUKA

(Received 25 May 2015; Revision Accepted 3 August 2015)

\begin{abstract}
A comparative performance evaluation of an existing and modified acha dehuller was carried out. The modifications undertaken on the existing dehuller were for the cylinder type, cylinder-concave clearance, cylinder speed and hopper opening. The modified acha dehuller was run at a higher cylinder and fan speeds of $2800 \mathrm{rpm}$ as against the existing cylinder and fan speeds of $934 \mathrm{rpm}$. The performance evaluation for the existing and modified acha dehullers determined were for their throughput, total grain loss, dehulling efficiency, acha recovery efficiency, cleaning efficiency and the dehullers' performance index. The performance of the existing and the modified machines were compared using t-Test at $p \leq 0.05$ to determine if the modified acha dehuller was significantly better than the existing machine. The results obtained showed that the modified machine was $30 \%, 31 \%, 30 \%$, $22 \%, 23 \%$ and $19 \%$ better than the existing machine for percentage of undehulled acha, total grain loss, dehulling efficiency, acha recovery efficiency, cleaning efficiency and dehuller performance index respectively. However, the throughput and percentage of blown acha of the two machines were not significantly different. The modified dehuller showed an improvement over the existing one.
\end{abstract}

KEYWORDS: Acha, fonio, dehuller, performance evaluation,

\section{INTRODUCTION}

Acha (Digitaria exilis) also known as fonio is a minor cereal in many countries of West Africa ethnic group where it is staple food crop for several millions of tribal people (Vietmeyer et al., 1996). Acha is grown in commercial quantity in various parts of Nigeria. It is grown in Bauchi, Kaduna, Kebbi, Plateau, Nassarawa, Niger, Gombe States and the Federal Capital Territory (FCT). Acha grains are very tiny with length and width dimensions of $1.604 \mathrm{~mm}$ and $0.864 \mathrm{~mm}$ respectively, and a weight of $0.529 \mathrm{~g}$ for one thousand grains (Philip, 2010), thus making it difficult to remove the brittle outer shell referred to as the hulls. The womenfolk are normally the ones tasked with this daunting responsibility of removing the hulls and they do it manually, which is a very painstaking and slow process. Pestle and mortar are used for the manual dehulling (pounding action), this action creates an impact and rubbing action to remove the hulls.

Various factors that affect the performance of crop processing equipment can be classified as crop, machine and operational parameters (Tandon et al., 1988; Singh and Singh, 1981; Hoki and Pickett, 1973). The crop parameters include the physico-mechanical properties of the crop, the moisture content and type of crop. The grain size is known to have significant effect on the clearance and adjustment of threshing and dehulling machines (Joshi, 1981; Adewumi and Olalusi, 1998; Adewumi and Igbeka, 1996). Normally, the concave-cylinder clearance should be greater than the mean axial dimension of the crop; otherwise, the grains would be damaged during threshing or dehulling (Adewumi and Igbeka, 1996). Grains with uniform size have higher threshing efficiency compared to non-uniform ones. While cereal could

Theresa K. Kaankuka, Department of Agric. and Environmental Engineering, University of Agriculture, Makurdi, Nigeria 
accommodate smaller concave setting and higher cylinder speed, legume crops such as beans and peas need a wider concave setting and lower speed to avoid cracking. Generally, the smaller and finer the grains to be shelled or threshed are, the smaller the required concave clearance and the higher the speed requirements (Klein and Harmond, 1986).

Evaluation involves measurement of machine performance under real farm conditions (Smith et al., 1994). The purpose of obtaining information by testing is to compare a device or machine with the requirement which it was developed to fulfill (Crossley and Kilgour, 1983). It is necessary to evaluate mechanical systems in order to obtain the optimal performance parameters for the systems.

In the last few decades, considerable effort has been expended by many researchers and research groups on the design and development of improved equipment for small and medium sized farms and farmers. Unfortunately farmer adoption has been well below the level hoped for, because of the low performance of equipment developed, this has resulted to a negative impact on standards of living. This low performance can be minimized by carrying out performance evaluation of the developed machine. The study is aimed at evaluating the performance of the existing and modified acha dehuller and compare if there was any significant improvement. Both acha dehullers were operated at their optimal performance parameters.

\subsection{MATERIALS AND METHODS}

The acha dehuller (Plate 1) comprises basically the hopper, the dehulling unit (cylinderconcave), the fan unit, dehulled acha chamber, air chamber and the cleaning chamber. The modifications undertaken for the modified acha dehuller were for the cylinder type, cylinderconcave clearance, cylinder speed and hopper opening.

Acha grains (Plate 2) are introduced into the dehulling chamber through the hopper (A). The removal of the hulls done in the dehulling unit (B) is achieved as acha grains were carried on the periphery of the cylinder and held there by centrifugal force as a result of the rotation of the cylinder. The differential movement between the cylinder and concave causes a rubbing action and the cylinder speed causes an impact action. These two actions (rubbing and impact), initiates and enhances the dehulling process. This is the same way the pestle effects the dehulling process during its downward and upward strokes in the mortar. The dehulled acha grains passes through the dehulled acha chamber (D) into the cleaning chamber $(F)$. Air generated by the fan in the fan unit $(C)$ passes through the air chamber $(E)$ to the cleaning chamber $(F)$ and cleans the dehulled acha by removing the chaff 


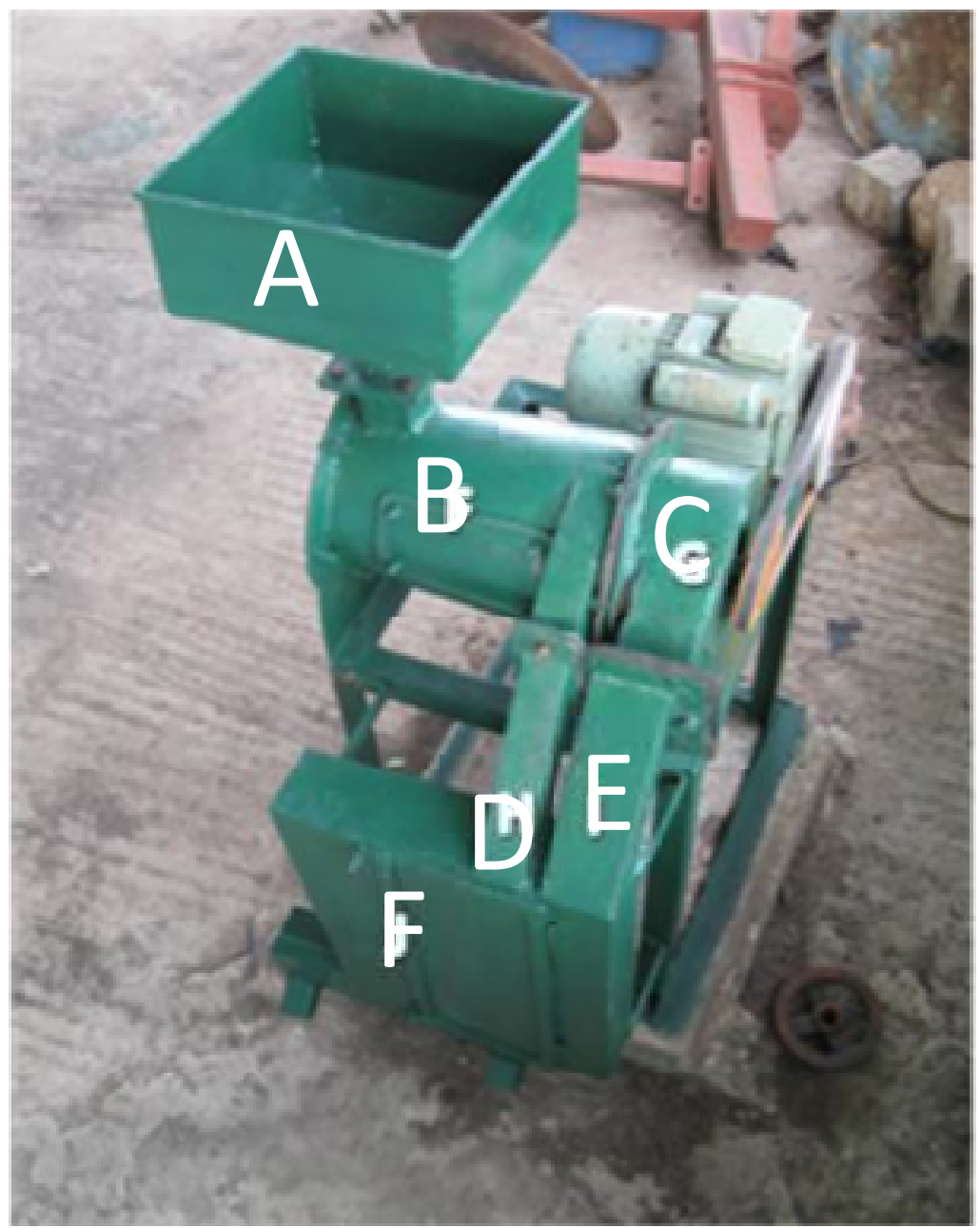

Plate 1: An acha dehuller

A. Hopper; B. Dehulling unit (cylinder-concave); C. Fan unit;

D. Dehulled acha chamber; E. Air chamber; F. Cleaning chamber

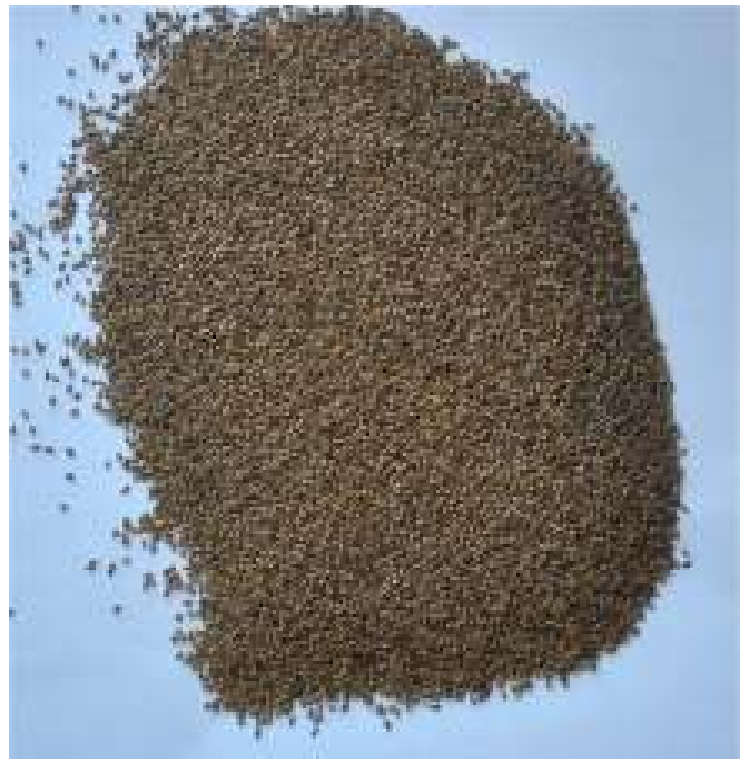

Plate 2: Undehulled acha 
The existing and modified acha dehullers were mounted on leveled and hard surfaces for the evaluation. The existing acha dehuller was evaluated at the designed speed of $934 \mathrm{rpm}$ with its open cylinder type (Plate 3 ). The modified acha dehuller was evaluated at a cylinder speed of $2800 \mathrm{rpm}$ with the use of an abrasive cylinder (Plate 4). The cylinder speed (2800 rpm) and abrasive cylinder type chosen to evaluate the modified acha dehuller was based on preliminary evaluation of the machine which was obtained as the optimum.
Undehulled acha $(5.6 \%$ moisture content) of $1 \mathrm{~kg}$ sample was used for each of the experiment and replicated thrice. Dehulling time was recorded using a stop watch. The weights of the undehulled acha grains, clean acha grains and chaff from both the grain and chaff outlets were measured using a digital weighing machine. The values of the weighed dehulled and undehulled acha, the weighed chaff and the time taken to dehull were used to determine the performance parameters for the acha dehullers.

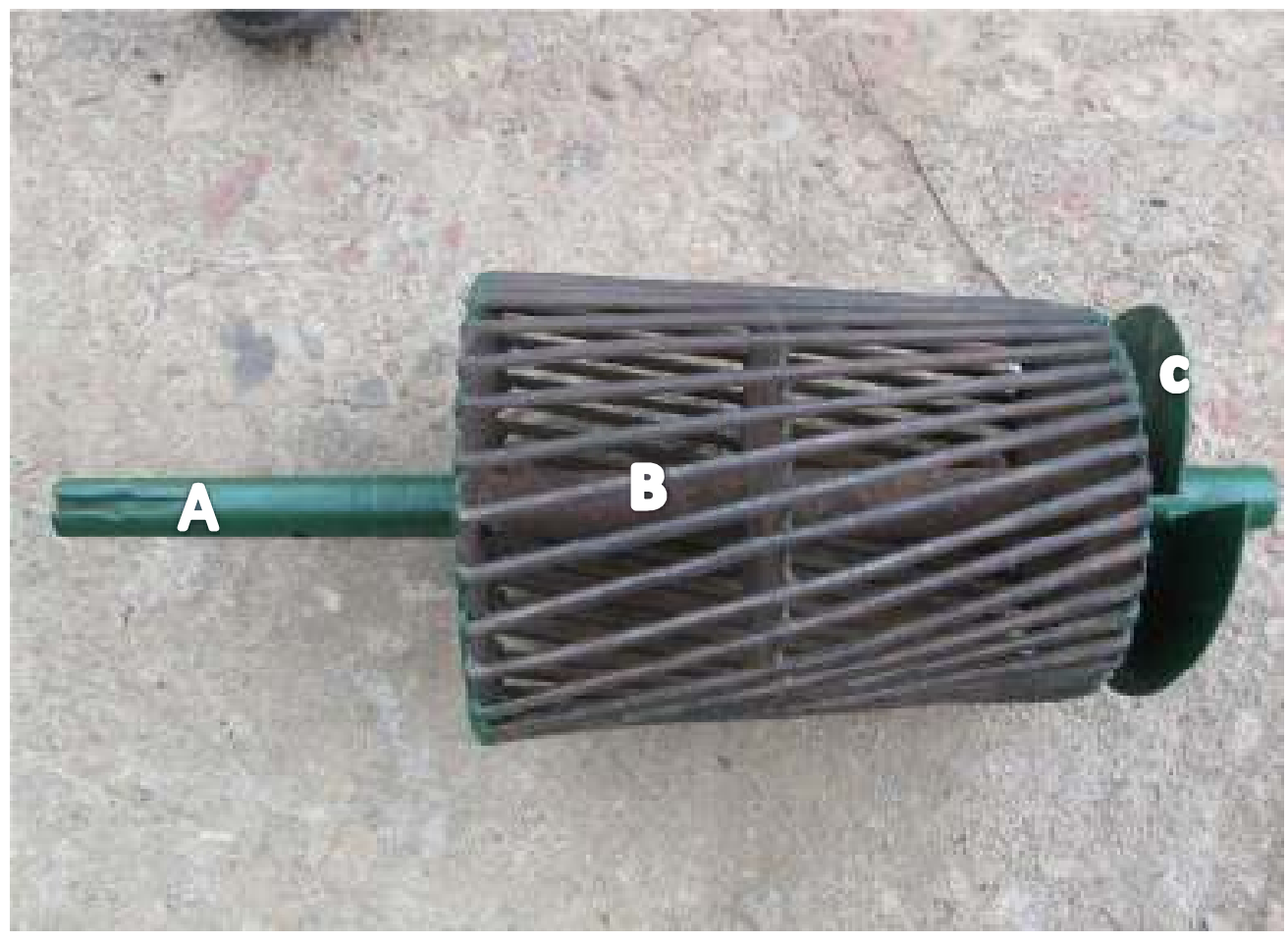

Plate 3: Open cylinder type

A. Shaft; B. Rod (5.6mm); C. Spiral conveyor 


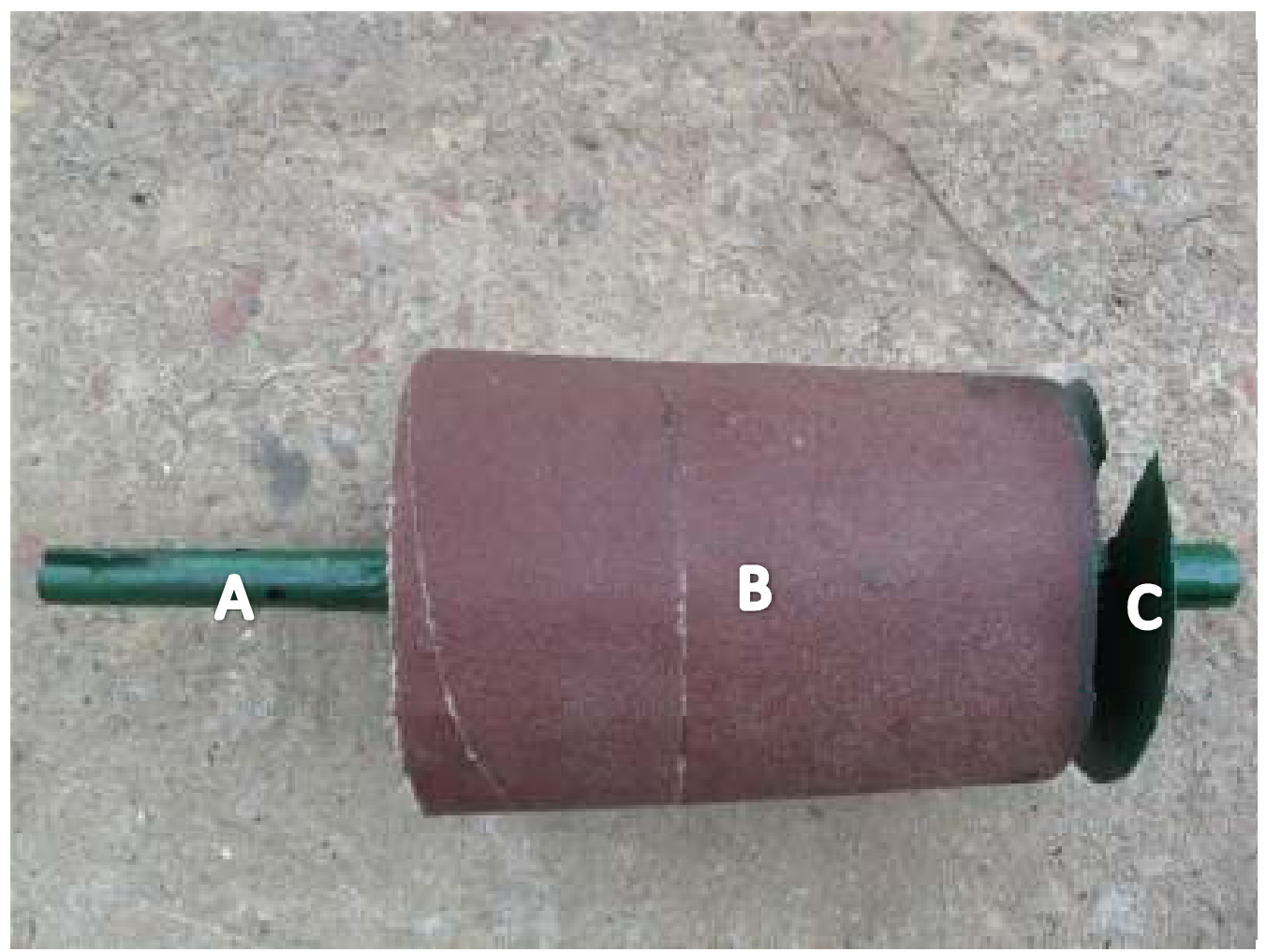

Plate 4: Abrasive cylinder type

A. Shaft; B. Abrasive material; C. Spiral conveyor

\subsection{PERFORMANCE DETERMINATION}

\subsection{Determination of Throughput $\left(F_{r}\right)$}

Throughput was taken as the mass of undehulled acha fed into the acha dehuller and the time taken to dehull it. Equation 1 was used to determine the throughput $\left(\mathrm{F}_{\mathrm{r}}\right)$.

$$
\mathrm{F}_{\mathrm{r}}=\frac{Q_{t}}{T}
$$

Where,

$Q_{\mathrm{t}}=$ total weight of acha fed into the dehuller, $\mathrm{kg}$ $\mathrm{T}=$ time taken to dehull sample, $\mathrm{hr}$

\subsection{Determination of Percentage Undehulled Acha (P)}

$$
\mathrm{P}=\frac{Q_{u} X 100}{Q_{t}}
$$

Where,

$\mathrm{P}=$ percentage of undehulled acha $(\%)$

$\mathrm{Q}_{\mathrm{u}}=$ weight of undehulled acha received at both the grain and chaff outlets, $\mathrm{kg}$

\subsection{Determination of Percentage Blown Acha ( $r$ )}

$$
r=\frac{Q X 100}{Q_{t}}
$$

Where,

$r=$ percentage of blown acha $(\%)$

$\mathrm{Q}=$ weight of dehulled acha received at chaff outlet, kg

\subsection{Determination of Total Acha Grain Loss $\left(T_{L}\right)$}

$\therefore$ Total Acha Grain Loss, $\mathrm{T}_{\mathrm{L}}$ is given by equation 4 as,

$$
T_{L}=P+r
$$


3.5. Determination of Dehulling Efficiency $\left(n_{D}\right)$ - this is the percentage by weight of dehulled acha received from all outlets of the dehuller with respect to total grain input.

$$
\eta_{D}=(100-P) \%
$$

\subsection{Determination of Acha Recovery} Efficiency $\left(\eta_{A}\right)$ this is the percentage by weight of dehulled grains collected from grain outlet with respect to the total grain input. This is expressed in equation 6 ,

$$
\eta_{\mathrm{A}}=\frac{Q_{o}}{Q_{t}} \%
$$

Where,

$Q_{0}=$ Weight of dehulled acha received at acha outlet, $\mathrm{kg}$

\subsection{Determination of Dehuller Cleaning}

Efficiency $\left(n_{c}\right)$ - this is the percentage

by weight of dehulled grains with respect to all products collected at the grain outlet (NIS $320: 1997)$. This is expressed in equation 7 as,

$$
\mathrm{\eta}_{\mathrm{c}}=\frac{Q_{S}}{Q_{A}} \%
$$

Where,

$Q_{S}=$ weight of foreign matter received at acha outlet, kg

$\mathrm{Q}_{\mathrm{A}}=$ weight of all products collected at acha outlet, $\mathrm{kg}$

3.8. Determination of Dehuller Performance Index (Epi) - this is a measure of the overall efficiency of the dehuller based on the cleaning efficiency and acha recovery efficiency. This is expressed in equation 8 as,

$$
\text { Epi }=\frac{\eta_{C} X \eta_{A}}{100}
$$

\subsection{RESULTS AND DISCUSSION}

\subsection{Results}

Table 1 is a summary of the comparative performance of the existing and improved acha dehullers.

TABLE 1: Summary of Comparative Performance of the Existing and Improved Acha Dehullers

\begin{tabular}{lllll}
\hline S/N & Parameter & $\begin{array}{l}\text { Existing } \\
\text { Machine }\end{array}$ & $\begin{array}{l}\text { Improved } \\
\text { Machine }\end{array}$ & $\begin{array}{l}\text { Improvement of } \\
\text { Modified over Existing } \\
\text { acha dehuller (\%) }\end{array}$ \\
\hline 1 & Throughput of dullers, $\mathrm{F}_{\mathrm{r}}(\mathrm{kg} / \mathrm{hr})$ & $50^{\mathrm{a}}$ & $48.67^{\mathrm{a}}$ & - \\
2 & Percentage of undehulled acha, $\mathrm{P}(\%)$ & $35^{\mathrm{a}}$ & $5^{\mathrm{b}}$ & 30 \\
3 & Percentage of blown acha, $\mathrm{r}(\%)$ & $2^{\mathrm{a}}$ & $3^{\mathrm{a}}$ & - \\
4 & Total acha grain loss, \% & $37^{\mathrm{a}}$ & $6^{\mathrm{b}}$ & 31 \\
5 & Dehulling efficiency, $\eta_{\mathrm{D}}(\%)$ & $65^{\mathrm{a}}$ & $95^{\mathrm{b}}$ & 30 \\
6 & Acha recovery efficiency, $\eta_{\mathrm{A}}(\%)$ & $48^{\mathrm{a}}$ & $70^{\mathrm{b}}$ & 22 \\
7 & Dehuller cleaning efficiency, $\eta_{\mathrm{C}}(\%)$ & $70^{\mathrm{a}}$ & $93^{\mathrm{b}}$ & 23 \\
8 & Dehuller performance index, $\mathrm{E}_{\mathrm{pi}}$ & $46^{\mathrm{a}}$ & $65^{\mathrm{b}}$ & 19 \\
\hline \multicolumn{5}{c}{ Means having the same letter in the same row are not statistically different from each other at $\mathrm{p} \leq 0.05$} \\
\multicolumn{5}{c}{ using t-Test }
\end{tabular}

\subsection{DISCUSSION}

A summary of the comparative performance of the existing and improved machine is shown in Table 1. There was no significant difference in the throughput between the existing and improved dehuller which had values of 50 and $48.67 \mathrm{~kg} / \mathrm{h}$ respectively. There was also no significant difference in the percentage blown acha which had values of $2 \%$ and $3 \%$ respectively. These non-significant differences could probably be because of the quantity of acha sample used for the experiment. However, significant differences exists between the existing and improved acha dehullers for percentage undehulled acha (35\% and $5 \%$ ), total grain loss $(37 \%$ and $6 \%)$, dehulling efficiency $(65 \%$ and $95 \%)$, acha recovery efficiency $(48 \%$ 
and $70 \%)$, dehuller cleaning efficiency $(70 \%$ and $93 \%)$ and dehuller performance index $(46 \%$ and $65 \%$ ) using $\mathrm{t}$-Test at $\mathrm{p} \leq 0.05$. The improved machine was $31 \%, 30 \%, 22 \%, 23 \%$ and $19 \%$ better than the existing machine in terms of total acha grain loss, dehulling efficiency, acha recovery efficiency, dehuller cleaning efficiency and dehuller performance index.

From the results (Table 1), the improved acha dehuller had a better performance over the existing one. The higher cylinder speed of 2800 rpm and the use of an abrasive cylinder would have created higher and better impact and rubbing actions for the acha grains in the dehulling chamber. The use of smaller cylinderconcave clearance $(10 \mathrm{~mm})$ could have also allowed for a better rubbing action and a longer differential movement for the grains for dehulling action. The differential movement between the cylinder and concave effects the dehulling process in the same way the pestle affects the dehulling process during it's downwards stroke in the mortar, thus resulting in better dehulling.

\section{CONCLUSION}

It can be concluded from the results obtained that the modified acha dehuller performed better than the existing acha dehuller. The modified acha dehuller was operated at a higher speed of 2800rpm which resulted in higher impact of the grains as against $943 \mathrm{rpm}$ used for the existing dehuller. From the results obtained, it is recommended that acha dehullers should be designed to operate on high speeds, small cylinder-concave clearance $(10 \mathrm{~mm})$ and use of abrasive cylinders for better impact and rubbing actions. This is in agreement with the report by (Klein and Harmond, 1986) that, the smaller and finer the grains to be shelled or threshed are, the smaller the required concave clearance and the higher the speed requirements.

\section{REFERENCES}

Adewumi, B. A and Igbeka, J. C., 1996. Performance evaluation of a burr type dehuller for locust bean. Research and Technical Journal, 5, (1): 1-8.

Adewumi, B. A and Olalusi, O. P., 1998. Performance of a manually operated concave type locust bean dehullers. Journal of Agricultural Technology, 6, (2): 23-30.
Crossley, P and Kilgour, J., 1983. Small Farm Mechanization for Developing Countries. Chichester, John Willey and Sons, NY. pp. 221-224.

Hoki, M and Pickett, L. R., 1973. Factors Affecting Mechanical Damage of navy beans. American Society of Agricultural Engineers Trans., 16, (6): 1554-1557.

Joshi, H. C., 1981. Design and selection of thresher parameters and components. Agricultural Mechanization in Asia, Africa and Latin America, 12: 61-68.

Klein, L. M and Harmond, J. E., 1986. Effect of varying cylinder speed and clearance of threshing cylinder in combing crimson clover. American Society of Agricultural Engineering Trans., 9, (4): $499-500$.

Nigerian Industrial Standard (NIS)., 1997. Standard Test code for grain and seed cleaners. NIS 320:1997. Standards Organization of Nigeria.

Philip, T. K., 2011. Development of an acha (Digitaria Exilis) dehulling machine. Unpublished Ph.D thesis, University of Agriculture, Makurdi, Benue State, Nigeria.

Singh, K. N and Singh, B., 1981. Effect of Crop and Machine Parameters on Threshing Effectiveness and Seed Quality of Soybean. Journal of Agricultural Engineering Research. 26: 349- 355.

Smith, D. W., Sims, B. G and O'Neil, D. H., 1994. Testing and Evaluation of Agricultural Machinery and Equipment: Principles and Practices. FAO Agricultural Services Bulletin, 110. FAO of the United Nations.

Tandon, S., Kirirohi, B. S and Sharma, P. R. S., 1988. Threshing efficiency of pulse using stepwise regression technique. Agricultural Mechanization in Asia, Africa, and Latin America, 19, (3): 55-57.

Vietmeyer, N. E., Borlaugh, N. E., Axte, J., Burton, J. R., Harlan, K. O and Rachie, O., 1996. Fonio (Acha). In: Lost Crop of Africa Vol. 1 Grains. BOSTID Publications National Academy Press, New York. 
